\title{
Influences of atmospheric and oceanic low-frequency climate fluctuations on European winter surface air temperatures (1870-2010)
}

\author{
François Borchi ${ }^{1}$, Yves M. Tourre ${ }^{1,2, *}$ \\ ${ }^{1}$ Météo-France, Centre National de Recherches Meteorologiques-GAME UMR-3589, Toulouse, France \\ ${ }^{2}$ Lamont-Doherty Earth Observatory (LDEO) of Columbia University, Palisades, New York, USA
}

\begin{abstract}
We isolated natural atmospheric and oceanic low-frequency climate fluctuations and its linkages with European winter surface air temperature (SAT) anomalies since 1870. Singular spectrum analysis was applied to SAT, North Atlantic sea surface temperature (SST), and the North Atlantic Oscillation (NAO) time series. The evolution of their low-frequency components was then compared with other time-series variability such as the Arctic Oscillation. The North Atlantic SST was found to be out of phase with the Atlantic sea level pressure and European SAT, following a $\sim 65 \mathrm{yr}$ climate fluctuation reminiscent of the Atlantic multi-decadal oscillation. Atlantic positive/negative SST anomalies preceded negative/positive European SAT anomalies by $\sim 6$ yr. Moreover, milder European winters occurred when a negative Atlantic multi-decadal phase overlapped a positive Arctic Oscillation phase (i.e. 1905-1915 and 1985-2000). The quasidecadal oscillation of SST and the NAO were in-phase and led positive/negative European SAT anomalies by approximately 1 yr. The low-frequency winter SAT variability represented $22.3 \%$ of the total variance. From the mid-1980s onward, when a rapid change in climate occurred, involving milder European winters, results showed that the NAO and the Arctic Oscillation phases both remained mostly positive. A strong polar vortex dominated during this period, minimizing meridional air-mass exchanges during winter. The anthropogenic component of climate change could modify the Atlantic thermohaline circulation, and with it the low-frequency variability of the North Atlantic SST, as well as the Arctic Oscillation variability, due to changes in the stratospheric thermal state, as shown elsewhere. These complex interactions between the Atlantic Ocean and the overlying atmosphere could have global socio-economical impacts in Europe during the 21st century.
\end{abstract}

KEY WORDS: AMO $\cdot$ Polar Vortex $\cdot$ Abrupt Climate Change $\cdot$ ACC

\section{INTRODUCTION}

Part of the spectrum of the Atlantic natural climate fluctuations from ocean-atmosphere coupling during the 20th century includes the low-frequency variability of: (1) the Atlantic Multi-decadal Oscillation (AMO, a 30 to 70 yr oscillation; Schlesinger \& Ramankutty 1994) which is linked to the Atlantic thermohaline circulation (Delworth \& Mann 2000); and (2) the Quasi-Decadal Oscillation (QDO, an 8 to $14 \mathrm{yr}$ oscillation in the coupled sea surface tempera-

${ }^{*}$ Corresponding author: yvestourre@aol.com ture and sea level pressure of the Atlantic basin; Tourre et al. 1999). Both fluctuations are found in long paleo-climatic records and biological proxies (i.e. tree-ring and coral time series; Gray et al. 2004, Hetzinger et al. 2008).

Combined air-sea interaction between natural low-frequency climate fluctuations affects seasonal European surface air temperature (SAT) variability (Sutton \& Hodson 2005, Gámiz-Fortis et al. 2010), the Sahelian drought, and the Atlantic hurricane power dissipation index (Tourre et al. 2010). The 21st cen-

(C) The authors 2014. Open Access under Creative Commons by Attribution Licence. Use, distribution and reproduction are unrestricted. Authors and original publication must be credited. 
tury climate change scenario issued by the IPCC (IPCC 2007) suggests that anthropogenic activity could interfere with natural low-frequency climate variability (Keenlyside et al. 2008).

It is thus of primary importance that we better understand the mechanisms and the role played by natural low-frequency climate fluctuations in European seasonal variability, in particular when combined with climate trends and changes. This study is a first step toward analyzing European winter SAT variability and comparing it with the Atlantic sea surface temperature (SST), the AMO and QDO, the North Atlantic Oscillation (NAO), and the Arctic Oscillation (AO). Differences between SAT trends, lowfrequency fluctuations, and rapid climate change are also discussed. We hope that this approach will help to (1) better understand the complexity of oceanatmosphere interactions involved at different time scales and (2) contribute to the adaptation and mitigation of impacts from climate variability and change.

\section{DATA AND METHODS}

\subsection{Datasets}

We used European anomalous winter (December to February) SAT (from 1961-1990 mean, following WMO recommendations) for the period 1870-2010, computed from the $5^{\circ} \times 5^{\circ}$ gridded fields available at the Koninklijk Nederlands Meteorologisch Instituut (http://climexp.knmi.nl, CRUTEM3, Brohan et al. 2006) averaged over western, central, and southern Europe (from $10^{\circ} \mathrm{E}$ to $20^{\circ} \mathrm{W}$ and $35^{\circ}$ to $60^{\circ} \mathrm{N}$ ). The Atlantic SST dataset on a $1^{\circ} \times 1^{\circ}$ grid is from HadlSST1.1, from 0 to $70^{\circ} \mathrm{W}$ and from the equator to $70^{\circ} \mathrm{N}$ (Rayner et al. 2003). The Atlantic SST tripole/horseshoe index as defined by Paeth et al. (2003) is also from HadlSST1.1. The tripole pattern basically consists of 2 areas: a positive/negative sign of SST anomalies east of Newfoundland and in the tropical eastern Atlantic (2 poles), and an area of positive/negative SST anomalies near the southeast coast of the US (third pole). The first 2 poles are simultaneously outof-phase with the third one.

The standardized NAO sea-level pressure index is taken from Jones et al. (1997) and is available at www.cru.uea.ac.uk/cru/data/nao/nao.dat.

Other climate indices such as the AO and the AMO are taken from the NOAA website (www.esrl.noaa. gov/psd/data/climateindices/). All monthly anomalies for the various time series and indices were computed from the 1961-1990 base period.

\subsection{Methods}

The singular spectrum analysis technique (Ghil et al. 2002) was applied to 4 time series: (1) European SAT, (2) Atlantic SST, (3) SST tripole time series, and (4) NAO time series. The technique is a powerful tool to isolate and distinguish between multiple period fluctuations and trends. We used 20 empirical orthogonal functions (EOFs) for the 4 time series. They explain $67,65,85$, and $61 \%$ of their total variances, respectively. Eigenvalues were obtained from a lagged-auto covariance matrix with dimension $\mathrm{M}$ (the window length). Since the time series are quite long (number of years, $\mathrm{N}=140$ ) a value of $\mathrm{M}=$ $140 / 3.5=40$ was used for the lags following Vautard \& Ghil (1989). While very little difference is found when $\mathrm{M}=35$, the noise is considerably reduced by using $\mathrm{M}=40$. The principal components have a temporal length of $\mathrm{N}-\mathrm{M}+1$. Eigenvalues are ranked in descending order. The basic assumption is that pairs of singular spectrum analysis (SSA) eigenvectors accounting for similar variance and displaying a quadrature type phase-relationship indicate possible climate fluctuations. Subsequent fluctuations were tested here against a red noise hypothesis which includes linear stochastic processes as in Allen \& Robertson (1996). Finally, Monte Carlo statistical tests for frequency coherence were run on all EOFs to better identify potential pairs (or fluctuations hereafter) at the $97.5 \%$ confidence level (Vautard et al. 1992).

\section{RESULTS}

\subsection{Variability of European winter SAT}

First, and prior to SSA, we compared time series of the European anomalous winter SAT and the NAO index (Fig. 1). The correlation between the 2 time series is $r=0.54$ (0.05 level of significance). Extreme winters were recorded in 1895, 1942, and 1963 (more than $-1.5^{\circ} \mathrm{C}$ anomalies) in the Parisian region (Rousseau 2009), and in 1995 and 2010 all over Europe. They occurred when the NAO was highly negative (1895, 1995) or stayed negative for a few years (1940-1943, 1953-1972). The discrepancies in the 2 time series during the 1907-1910 period might be related to the Tunguska event (a burst of comet fragments in Siberia on 30 June 1908, with dust clouds reaching $40 \mathrm{~km}$ in altitude over Europe; Bagnall 1988). Low-frequency NAO variability is noticeable with an upward trend from the late 1960s until the early 1990s, and a reversed trend until 2010. It is worth noting that since 


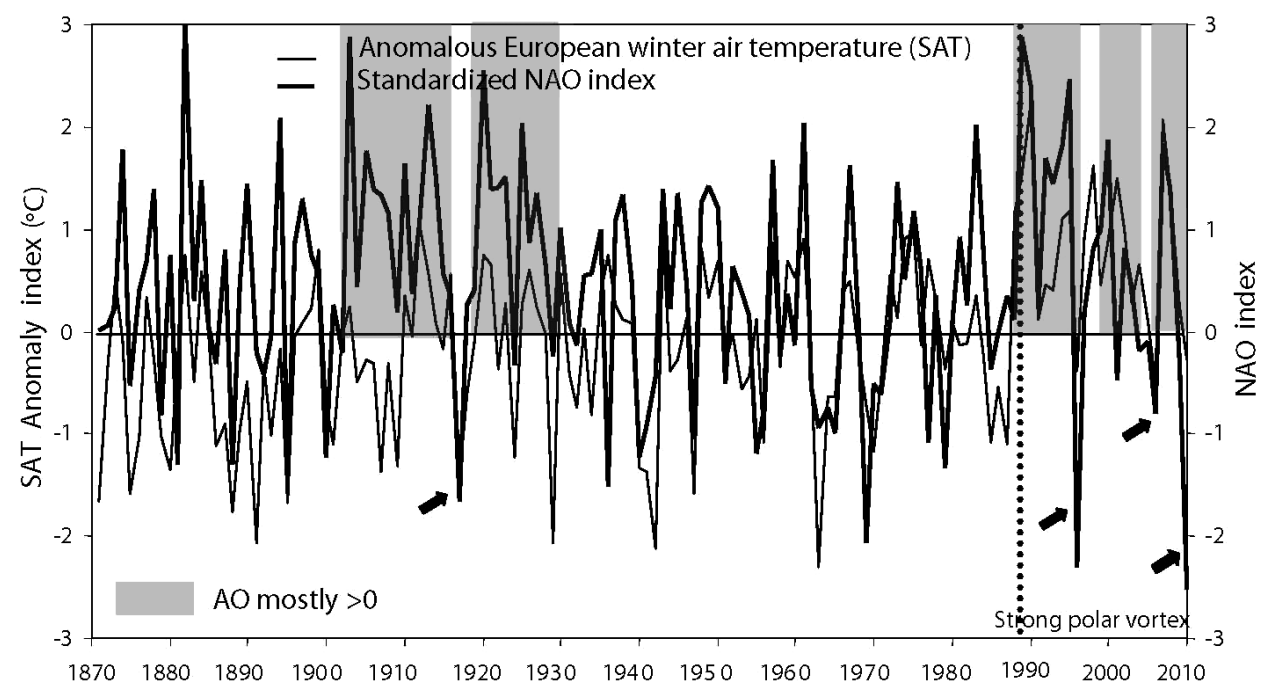

Fig. 1. Anomalous (from 1961-1990 mean) European winter surface air temperature (SAT; thin black line; left ordinates) and standardized NAO index (thick black line; right ordinates) from 1870-2010. Gray shadings: periods when the Arctic Oscillation (AO) was mostly positive. The dotted line in 1988 represents the start of the recent abrupt climate change. Arrows: very cold winters embedded in periods with milder winters. The obvious discrepancy from 1905 and 1917 is when negative European winter temperatures are present along with persistent positive AO (June 1908 corresponds to the Tunguska explosion in Siberia)

1870, the lowest NAO anomalies occurred in 2010 after the eruption of the Eyjafjallajökull Icelandic volcano in April. Extreme negative values of NAO (1918, $1936,1969,1995,2010)$, correspond to 40 to $60 \%$ of frequency when NAO $<0$ (Compo et al. 2011). Periods when the winter temperature anomalies were mostly positive (1909-1930 and 1988-2008) occurred when the NAO was also mostly positive. Moreover, 1988 was not only the warmest winter in France during the 20th century $\left(+2.2^{\circ} \mathrm{C}\right.$ anomaly), but also the following winters when SAT anomalies remained mostly positive until at least 2008. This rapid change was associated with a mean air temperature increase of $1^{\circ} \mathrm{C}$ during the 20th century (an increase of $0.8^{\circ} \mathrm{C}$ for the winter mean $\mathrm{SAT}$, of $0.7^{\circ} \mathrm{C}$ for the winter minimum $\mathrm{SAT}$, and of $1.1^{\circ} \mathrm{C}$ for the winter maximum SAT). The years 1917, 1996, 2003-2004, 2005-2006, and 2009-2010 were years when the NAO was strongly negative (see black arrows in Fig. 1), or occurred after strong volcanic eruptions like in Montserrat (Cole et al. 2002), which corresponds to very cold European winters (Self 2006, Scaife \& Knight 2008).

\subsection{Low-frequency variability of European winter SAT}

The previous observations required further analyses to highlight possible climate fluctuations in the time series and indices presented in Section 2.1. This was achieved by using the SSA technique. Only lowfrequency variability will be presented in this paper. In Fig. 2a, 3 time series are analyzed: mean SST in the North Atlantic, the NAO, and the detrended European winter temperature. EOF 2 was kept for the SST $(20 \%$ of total variance) since it compares closely to the AMO, while EOFs 7 and 10 represented the low frequency of the NAO variability (6.5\% of total variance) and EOFs 1 and 2 for SAT explained $17 \%$ of the total variance. A $\sim 65$ yr period (a multi-decadal fluctuation) is well represented in all 3 reconstructed time series (Fig. 2a). The outof-phase relationship between the SST and sea level pressure is striking. The SST basically changed phases: positive in 1870-1895; negative in 1896-1932; positive in 1933-1968; and negative in 1969-2001. These periods and phase changes coincide approximately with that of the AMO (Knight et al. 2005). The AMO during the last $140 \mathrm{yr}$ also displayed 2 periods when overall milder (colder) winters occurred: 19031928 (1870-1902) and 1982-2008 (1928-1982). Interestingly, the 2 isolated cold winters of 1906-1907 and 1908-1909, when the NAO was mostly positive, occurred at times of intense volcanic eruptions of Mount Vesuvius (Glangeaud 1907) and Mount Teide (Perret 1911), with possible stratospheric and radiative impacts. European winter SAT anomalies also changed phases in 1902, 1929, and 1982, thus following the joint SST/NAO low-frequency variability. The SST multi-decadal oscillation preceded the 


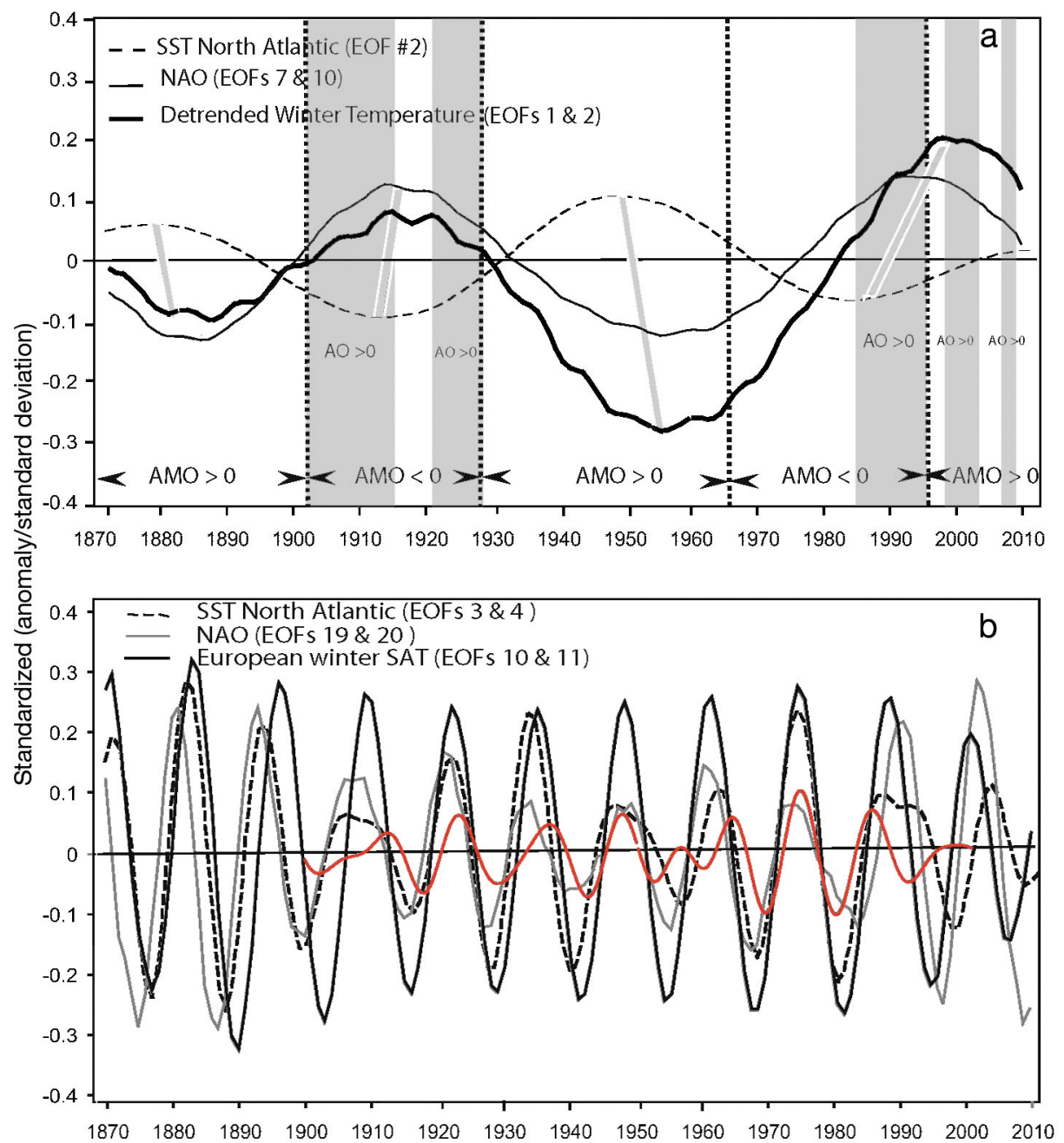

Fig. 2. (a) Multi-decadal oscillation ( 65 yr): standardized (i.e. anomalies divided by the standard deviation) values of sea surface temperature (SST) anomalies in the northern Atlantic (second empirical orthogonal function [EOF], dashed line), NAO (EOFs 7 and 10 from singular spectrum analysis [SSA], thin black line), and detrended European winter air temperatures (EOFs 1 and 2 from SSA, thick black line) from 1870-2010. The Atlantic Multi-decadal Oscillation (AMO) phases are given at the bottom, separated by dotted lines. Arctic Oscillation (AO) >0 periods are also displayed (gray shading). The lagged relationships between SST and European winter air temperatures are emphasized by the thick gray slanted lines. (b) Quasidecadal oscillation (period of $13.3 \mathrm{yr}$ ): standardized values for SST (EOFs 3 and 4, dashed line), NAO (EOFs 19 and 20, grey line), and European winter surface air temperatures, SATs (EOFs 10 and 11, thick black line) are given. Red line: joint SST/sea level pressure time series for the 20th century only, for comparison. During the last $20 \mathrm{yr}$ when persistent winters warming occurred, temperature extremes actually preceded NAO extremes for unknown reasons

European winter SAT fluctuations by $\sim 6 \mathrm{yr}$ with a mean lagged correlation $\mathrm{r}=0.83$ (see grey slanted lines in Fig. 2a). AMO was negative when the SST component was also negative. Winters rapidly became milder when a positive NAO was evident.

In Fig. 2b, EOFs 3 and 4 represent the time series of the SST tripole/horseshoe (10\% of total variance) variability (similar to the index computed by Paeth et al. 2003), EOFs 19 and 20 represent the time series of the NAO (3.3\% of total variance), and EOFs 10 and 11 represent the time series of the European winter SAT (5.3\% of total variance). They are all associated with the quasi-decadal component of the NAO. The quasi-decadal fluctuation displayed a positive phase, which led the SST tripole/horseshoe positive phase and the European positive winter SAT anomalies by several months. A maximum correlation of $r=0.78$ is found for an approximate 1 yr lead. From the mid1980s until 2005, European winter air temperature preceded NAO and SST by 1 yr for unknown reasons. It should be noted that this is the time when an abrupt climate change occurred whilst the AO remained mostly positive (see next section). Finally, EOFs 1 and 2 of the detrended European winter SAT 
Table 1. European winter surface air temperature (SAT), Atlantic sea surface temperature (SST), Atlantic multi-decadal oscillation (AMO), North Atlantic Oscillation (NAO), Arctic Oscillation (AO), and SAT variability associated with the quasi-decadal oscillation (QDO). The signs of anomalous low-frequency phasing are given (blue shading: colder and/ or smaller indices; red shading: warmer and/or larger indices). Periods shaded in gray correspond to AO mainly $>0$ as in Fig. 2b. The anomalous amplitude of the SAT (QDO) variability (positive/negative in red/blue) from Fig. $2 b$ is provided to illustrate the contributing components of the SAT low-frequency signals: the multi-decadal oscillation and the QDO

\begin{tabular}{|c|l|l|l|l|l|l|}
\hline Periods & SAT & SST & AMO & NAO & AO & SAT (QDO) \\
\hline $1870-1896$ & $<0$ & $>0$ & $>0$ & $<0$ & & \\
$1896-1898$ & $<0$ & $<0$ & $>0$ & $<0$ & & \\
$1898-1902$ & $<0$ & $<0$ & $>0$ & $<0$ & & \\
\hline $1902-1915$ & $>0$ & $<0$ & $<0$ & $>0$ & $>0$ & \\
$1915-1922$ & $>0$ & $<0$ & $<0$ & $>0$ & & \\
$1922-1927$ & $>0$ & $<0$ & $<0$ & $>0$ & $>0$ & \\
\hline $1927-1930$ & $<0$ & $<0$ & $>0$ & $>0$ & & \\
$1930-1932$ & $<0$ & $<0$ & $>0$ & $>0$ & & \\
$1932-1966$ & $<0$ & $>0$ & $>0$ & $<0$ & & \\
$1966-1969$ & $<0$ & $>0$ & $<0$ & $<0$ & & \\
$1969-1973$ & $<0$ & $>0$ & $<0$ & $<0$ & & \\
$1973-1982$ & $<0$ & $<0$ & $<0$ & $>0$ & & \\
\hline $1982-1985$ & $>0$ & $<0$ & $<0$ & $>0$ & & \\
$1985-1996$ & $>0$ & $<0$ & $<0$ & $>0$ & $>0$ & \\
$1996-1998$ & $>0$ & $<0$ & $>0$ & $>0$ & & \\
$1998-2003$ & $>0$ & $<0$ & $>0$ & $>0$ & $>0$ & \\
$2003-2006$ & $>0$ & $>0$ & $>0$ & $>0$ & & \\
$2006-2008$ & $>0$ & $>0$ & $>0$ & $>0$ & $>0$ & \\
\hline
\end{tabular}

(Fig. 1) combined with EOFs 10 and 11, which represent quasi-decadal fluctuations in European winter SAT (Fig. 2b), represent $22.3 \%$ of the total SAT variance. The superimposed time series (red line) for the 20th century only, is provided to compare the quasidecadal amplitude functions obtained from an independent climate study of the joint SST/sea-level pressure (SLP) variability in the Atlantic basin by Tourre et al. (2010).
The above results are synthesized in Table 1, where the anomalous low-frequency variability of the discussed indices are displayed along with SAT and SST anomalies, while the individual timelines are given from 1870 until 2008.

\section{DISCUSSION AND CONCLUSION}

In this study, the main assumption was that pairs of SSA eigenvectors accounting for similar variance and displaying a quadrature-type phase relationship indicate possible climate fluctuations. Thus using SSA, we highlight the influences of 2 well documented low-frequency climate fluctuations elsewhere in the literature (from joint SST/SLP analyses, see Tourre et al. 2010) - i.e. a global multi-decadal oscillation (and its Atlantic footprint or AMO) and the QDO - on the intensity of European winter SATs since 1870. Here spatial and temporal averaged temperatures (i.e. yearly winter values for all of Europe) were used. Nevertheless, when additional tests were run, coherence between winter SATs were found using time series from European sub-regions or countries such as France during the 20th century. For example, the correlation between the winter SAT time series of Europe and France is $r=0.92$ (Fig. 3). This high correlation is not surprising; for example, from an EOF analysis of a European temperature dataset, Gámiz-Fortis et al. (2010) found that spatial loadings in France belong to 3 European leading modes (i.e. $65.6 \%$ of total variance).

For the multi-decadal oscillation, the SST/AMO time-series phase changes preceded the European phase changes of the detrended winter SAT by $\sim 6 \mathrm{yr}$

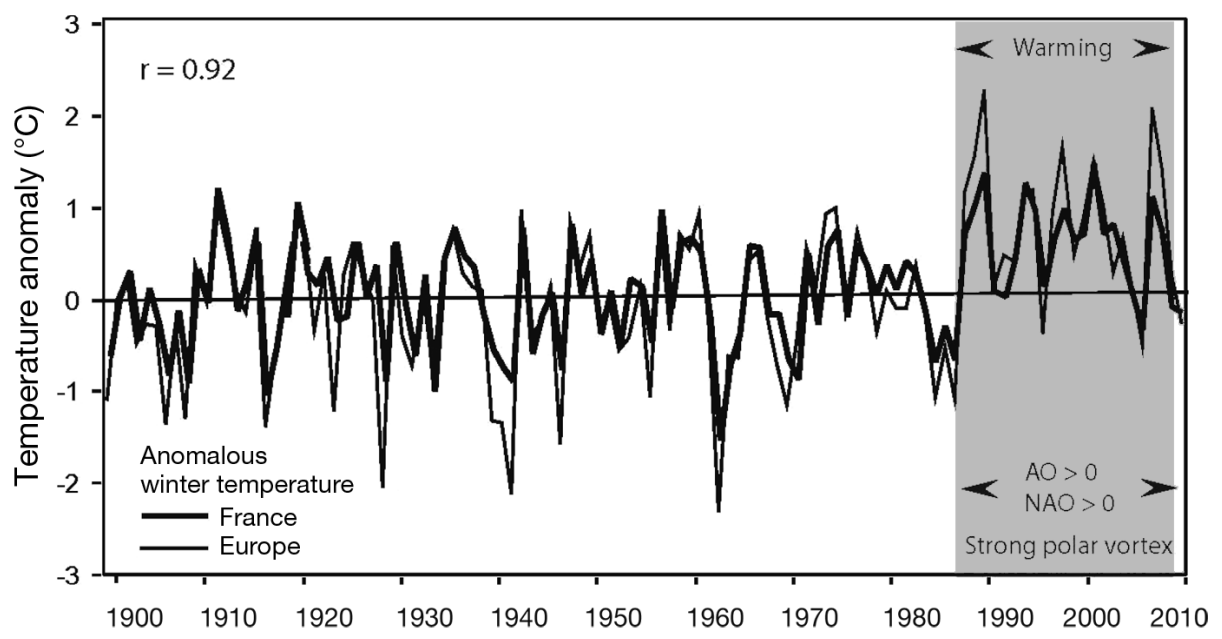

Fig. 3. Anomalous (from 1961-1990 mean) winter surface air temperature for Europe (thin black line) and France (thick black line) during the 20th century, and correlation between these time series (top left of graph). No trend is obvious from 1900 until 1987 
(Fig. 2a). The multi-decadal variability of the NAO could be associated with low-frequency anomalous salinity and heat fluxes in the Labrador Sea (Straneo, 2006). This could also modulate the Atlantic meridional overturning circulation (Álvarez-García et al. 2008). In Fig. 2a it can be seen that NAO variability is also out-of-phase with low-frequency SST variability for the full period and in-phase with that of European winter temperature evolution from 1870 until the mid-1970s. The opposite phases in SST and NAO imply a negative feedback of the northern Atlantic Ocean on the overlying atmosphere. Thus mechanisms possibly involved with the multi-decadal oscillation on SAT could be as follows: (1) slow evolution of the Atlantic thermohaline circulation as in Delworth \& Mann (2000), (2) negative feedback of the Atlantic thermohaline circulation on SST (Kerr 2000), and (3) the multi-decadal component of NAO with a tendency for lower sea level pressure during European winters, with a 6 yr lag (Hurrell \& van Loon 1997).

For the QDO during the last $140 \mathrm{yr}$, the $13.3 \mathrm{yr}$ fluctuation preceded, the Atlantic SST variability by a small margin (i.e. by several months). Atmospheric heat flux negative feedback is thought to be generated by the NAO on this time scale (Schneider \& Fan 2010). Note that these mechanisms differ from positive feedbacks when 'SST configuration precedes NAO phase', as proposed by Cjaza \& Frankignoul (2002). Whilst the quasi-decadal Atlantic meridional overturning could provide a delayed negative feedback (Latif et al. 2007), a stronger Atlantic meridional overturning could be involved with the inter-tropical convergence zone (ITCZ) located farther north in the tropical North Atlantic. Fresher waters could then be advected northward, contributing to thermohaline circulation variability on this time scale (Vellinga \& Wu 2004). Apart from the period 1985-2005, positive NAO phases were found, along with positive SST phases (i.e. positive SST anomalies east of the USA expanding into the Sargasso Sea and negative SST anomalies east of Newfoundland expanding into the Irminger Sea along with tropical North Atlantic negative anomalies). Thus the European atmospheric circulation is strongly modified in winter, leading to positive air temperature anomalies. Lampart (2004) reproduced these patterns through canonical correlation analysis during winter. The atmospheric response to the SST anomalies on this time scale seems to enhance winter-to-winter NAO anomalies, thus modulating air mass exchanges between high and mid-latitudes. This could lead to intrinsic so-called 'weather regimes' identified by Cassou et al. (2007).
The specific mechanisms remain to be fully explained and modeled. Finally, changes in the above quasi-decadal anomalies during the last $25 \mathrm{yr}$ of the time series, when winter SAT anomalies preceded NAO anomalies, remain unclear.

Super-imposed on the low-frequency variability, a recent abrupt and long-lasting climate change started in 1988 when the positive phase of the AO overlapped the negative phase of the AMO and lasted at least until 2008. The gray shaded zone in Fig. 3 highlights the period during which the rapid climate change occurred, and when winters became (rapidly) milder until 2008. This is the period when the AO and NAO were both mostly positive and were possibly associated with a strong polar vortex.

This abrupt climate change contributed to the temperature increase during the 20th century (see section 3.1). Persistent positive phases of the AO coincide with the periods when European winters rapidly became and stayed milder, i.e. during 1902-1927 and 1985-2008 (Table 1). From 1988-2008 (Fig. 3), 10 of the warmest winters occurred with $\mathrm{a}+2.0^{\circ} \mathrm{C}$ anomaly in 1989-1990 and with a $1.1^{\circ} \mathrm{C}$ anomaly in $2007-$ 2008. This abrupt change (Bellamy \& Hulme 2011) is indicative of the role played by a stronger stratospheric polar vortex on the AO/NAO positive phases (Tanaka \& Tokinaga 2002). An increase of $7 \mathrm{~m} \mathrm{~s}^{-1}$ increase in the polar vortex is associated with an 11 to $12 \mathrm{hPa}$ in the NAO index (Scaife et al. 2005). A stronger polar vortex associated with a stronger polar vortex oscillation index (Paz et al. 2008) contributes to warmer winter SAT in the entire northern hemisphere (Douville, 2009), including Europe. Long periods (or trends) of positive $\mathrm{AO}$ are consistent with a colder stratosphere, a decrease in ozone concentration, and an increase in greenhouse gas concentrations (Shindell et al. 1999, Comiso et al. 2008).

Finally, embedded in milder winters periods (Figs. 1 \& 3), very cold winters like in 1916-1917 and 2005-2006 could be associated with strong volcanic eruptions (see section 3.1) and/or the short-lived sudden stratospheric warming (Rex et al. 2006), leading to rapid breakdown of the stratospheric polar vortex. This could be due to dynamical forcing of upward propagating planetary waves from the troposphere as proposed by Matsuno (1971). A recent and strong sudden stratospheric warming occurred during the 2009-2010 winter (Kuttippurath \& Nikulin 2012).

In summary, results presented in this study using SSA strengthen the idea that, besides the anthropogenic component of climate change, the lowfrequency climate variability of the European winter SAT is modulated by the natural multi-decadal vari- 
ability of both the Atlantic Ocean and its coupled atmosphere. The intensity of European winters is also influenced by the quasi-decadal variability of the NAO and the AO. This low-frequency variability contributes to a variance of the same order of magnitude as that of the anthropogenic change and temperature tendency recently proposed by Parker et al. (2007). It is recognized that climate change may modify the above result since recent climate studies have shown that the northern winter wave driving the Brewer-Dobson Circulation is enhanced by the increase in greenhouse gas concentrations (Shindell et al. 1998, Haklander et al. 2008). The overall impact is a strong stratospheric cooling as observed in the 1990s and an increase in the polar stratospheric cloud volume (Newman et al. 2001). Since 2008, the AO seems to display more neutral or slightly negative phases (Overland \& Wang 2005). Nevertheless, it is still not clear whether radiative effects from increased carbon dioxide concentration will continue to cool the stratosphere, and/or whether the polar vortex will remain stronger/weaker (Waugh \& Polvani 2010) in the near future.

Understanding natural low-frequency climate variability, abrupt climate change, and very short climate events within an anthropogenic climate change context is a research priority, since such variability may have significant socio-economical impacts. European food production associated with low-frequency climate changes may also necessitate regional changes in agricultural practices as adaptive mechanism (Xu et al. 2012, Bebber et al. 2013).

Acknowledgements. Y.M.T. thanks M. Purdy (Columbia University's Executive Vice President for Research) and A. Lerner-Lam (former director of LDEO of Columbia University) and P. Dandin (Climatology Department of MétéoFrance) for their unconditional support. This is LDEO contribution no. 77411 .

\section{LITERATURE CITED}

Allen MR, Robertson AW (1996) Distinguishing modulated oscillations from coloured noise in multivariate datasets. Clim Dyn 12:775-784

> Álvarez-García F, Latif M, Biastoch A (2008) On multidecadal and quasi-decadal North Atlantic variability. J Clim 21:3433-3452

Bagnall P (1988) The Tunguska event. J Br Astronom Assoc 98:184-188

> Bebber DP, Ramotowski MAT, Gurr SJ (2013) Crop pests and pathogens move polewards in a warming world. Nat Clim Change 3:985-988

Bellamy R, Hulme M (2011) Beyond the tipping point: understanding perceptions of abrupt climate change and their implications. Weather Clim Soc 3:48-60
Brohan P, Kennedy JJ, Harris I, Tett SFB, Jones PD (2006) Uncertainty estimates in regional and global observed temperature changes: a new dataset from 1950. J Geophys Res 111:D12106, doi:10.1029/2005JD006548

$>$ Cassou C, Deser C, Alexander MA (2007) Investigating the impact of reemerging sea surface temperature anomalies on the winter atmospheric circulation over the North Atlantic. J Clim 20:3510-3526

Cole PD, Calder ES, Sparks RSJ, Clarke AB and others (2002) Deposits from dome-collapse and fountain-collapse pyroclastic flows at Soufrière Hills Volcano, Montserrat. Geol Soc Lond Mem 21:231-262

Comiso JC, Parkinson CL, Gersten R, Stock L (2008) Accelerated decline in the Arctic sea ice cover. Geophys Res Lett 35:L01703, doi:10.1029/2007GL031972

Compo GP, Whitaker JS, Sardeshmukh PD, Matsui N and others (2011) The Twentieth Century Reanalysis Project. QJR Meteorol Soc 137:1-28

Czaja A, Frankignoul C (2002) Observed impact of Atlantic SST anomalies on the North Atlantic Oscillation. J Clim 15:606-623

> Delworth TL, Mann ME (2000) Observed and simulated multi-decadal variability in the Northern Hemisphere. Clim Dyn 16:661-676

> Douville H (2009) Stratospheric polar vortex influence on Northern Hemisphere winter climate variability. Geophys Res Lett 36:L18703, doi:10.1029/2009GL039334

> Gámiz-Fortis SR, Esteban-Parra MJ, Pozo-Vásquez D, Castro-Díez Y (2010) Variability of the monthly European temperature and its association with the Atlantic seasurface temperature from inter-annual to multi-decadal scales. Int J Climatol 31:2115-2140

> Ghil M, Allen MR, Dettinger MD, Ide K and others (2002) Advanced spectral methods for climatic time series. Rev Geophys 40:3-1-3-41

Glangeaud P (1907) L'éruption du Vésuve en Avril 1906. Ann Georgr 88:289-295

> Gray ST, Graumlich LJ, Betancourt JL, Pederson GT (2004) A tree-ring based reconstruction of the Atlantic Multidecadal Oscillation since 1567 A.D. Geophys Res Lett 31: L12205, doi:10.1029/2004GL019932

Haklander A, Siegmund PC, Sigmond M, Kelder HM (2008) How does the northern-winter wave driving of the Brewer-Dobson circulation increase in an enhanced- $\mathrm{CO}_{2}$ climate simulation? Geophys Res Lett 35:L07702, doi:10. 1029/2007GL033054

- Hetzinger S, Pfeiffer M, Dullo WC, Keenlyside N, Latif M, Zinke J (2008) Caribbean coral tracks Atlantic Multidecadal Oscillation and past hurricane activity. Geology 36:11-14

> Hurrell JW, van Loon H (1997) Decadal variations associated with the North Atlantic Oscillation. Clim Change 36: 301-326

IPCC (Intergovernmental Panel on Climate Change) (2007) Climate change 2007: synthesis report. Contribution of Working Groups I, II and III to the Fourth Assessment Report of the IPCC. Cambridge University Press, Cambridge. www.ipcc.ch/publications_and_data/ar4/syr/en/ contents.html

Jones PD, Jonsson T, Wheeler D (1997) Extension to the North Atlantic Oscillation index using early instrumental pressure observations from Gibraltar and southwest Iceland. Int J Climatol 17:1433-1450

Keenlyside NS, Latif M, Jungclaus J, Kornblueh L, Roeckner E (2008) Advancing decadal scale climate prediction in the 
North Atlantic sector. Nature 453:84-88

Kerr RA (2000) A north Atlantic pacemaker for the centuries. Science 288:1984-1985

Knight J, Allan RJ, Folland CK, Vellinga M, Mann ME (2005) A signature of persistent natural thermohaline circulation cycles in observed climate. Geophys Res Lett 32:L20708, doi:10.1029/2005GL024233

Kuttippurath J, Nikulin G (2012) The sudden stratospheric warming of the Arctic winter 2009/2010: comparison to other recent warm winters. Atmos Chem Phys Discuss 12:7243-7271

Lampart N (2004) Relationship between winter European land and North Atlantic sea surface temperatures in the 20th century. Masters thesis, Universität Bern

Latif M, Böning W, Willebrand J, Biastoch A, Alvarez-Garcia F, Keenlyside N, Pohlmann B (2007) Decadal to multidecadal variability of the Atlantic MOC: mechanisms and predictability. AGU Geophys Monogr Ser173:149-166, doi:10.1029/173GM11

> Matsuno T (1971) Circulation and waves in the middle atmosphere in winter. Space Sci Rev 34:387-396

> Newman PA, Nash ER, Rosenfield J (2001) What controls the temperature of the Arctic stratosphere during the spring? J Geophys Res 106:19999-20010

Overland JE, Wang M (2005) The Arctic climate paradox: the recent decrease of the Arctic Oscillation. Geophys Res Lett 32:L06701, doi:10.1029/2004GL021752

Paeth H, Latif M, Hense A (2003) Global SST influence on twentieth century NAO variability. Clim Dyn 21:63-75

Parker D, Folland C, Scaife A, Knight J, Colman A, Baines P, Dong B (2007) Decadal to multi-decadal variability and the climate change background. J Geophys Res 112: D18115, doi:10.1029/2007JD008411

Paz S, Tourre YM, Brolley J (2008) Multitemporal climate variability over the Atlantic Ocean and Eurasia: linkages with Mediterranean and West African climate. Atmos Sci Lett 9:196-201

Perret FA (1911) The volcanic eruption at Tenerife in the autumn of 1909. Z Vulkanol 1:20-31

Rayner NA, Parker DE, Horton EB, Folland K and others (2003) Global analyses of SST, sea ice and night marine air temperature since the late nineteenth century. J Geophys Res 108:4407, doi:10.1029/2002JD002670

Rex M, Salawitch RJ, Deckelmann H, von der Gathen P and others (2006) Arctic winter 2005: implications for stratospheric ozone loss and climate change. Geophys Res Lett 33:L23808, doi:10.1029/2006GL026731

Rousseau D (2009) Les températures mensuelles en région parisienne de 1676 à 2008. Meteorologie 8:43-55

Scaife AA, Knight JR (2008) Ensemble simulations of the

Editorial responsibility: Oliver Frauenfeld,

College Station, Texas, USA cold European winter of 2005-2006. QJR Meteorol Soc 134:1647-1659

Scaife AA, Knight JR, Vallis GF, Folland CK (2005) A stratospheric influence on the winter NAO and North Atlantic surface climate. Geophys Res Lett 32:L18715, doi:10.1029/ 2005GL023226

> Schlesinger ME, Ramankutty N (1994) An oscillation in the global climate system of period $65-70$ years. Nature 367 : 723-726

Schneider EK, Fan M (2010) Observed decadal North Atlantic tripole SST variability. II. Diagnosis of mechanisms. J Atmos Sci 69:51-64

Self S (2006) The effects and consequences of very large explosive volcanic eruptions. Philos Trans R Soc Lond A Math Phys Eng Sci 364:2073-2097

Shindell DT, Rind D, Lonergan P (1998) Increased polar stratospheric ozone losses and delayed eventual recovery owing to increasing greenhouse-gas concentrations. Nature 392:589-592

Shindell DT, Miller RL, Schmidt GA, Pandolfo L (1999) Simulation of recent northern winter climate trends by greenhouse-gas forcing. Nature 399:452-455

Straneo F (2006) Heat and freshwater transport through the Central Labrador Sea. J Phys Oceanogr 36:606-628

Sutton RT, Hodson DLR (2005) Atlantic Ocean forcing of North American and European summer climate. Science 309:115-118

Tanaka HL, Tokinaga H (2002) Baroclinic instability in high latitudes induced by polar vortex: a connection to the Arctic Oscillation. J Atmos Sci 59:69-82

Tourre YM, Rajagopalan B, Kushnir Y (1999) Dominant patterns of climate variability in the Atlantic Ocean during the last 136 years. J Clim 12:2285-2299

Tourre YM, Paz S, Kushnir Y, White WB (2010) Lowfrequency climate variability in the Atlantic basin during the 20th century. Atmos Sci Lett 11:180-185

> Vautard R, Ghil M (1989) Singular spectrum analysis in non linear dynamics, with applications to paleo-climatic time-series. Physica D 35:395-424

> Vautard R, Yiou P, Ghil M (1992) Singular spectrum analysis: a toolkit for short, noisy chaotic signals. Physica D 58: 95-126

> Vellinga M, Wu P (2004) Low-latitude freshwater influence on centennial variability of the Atlantic Thermohaline Circulation. J Clim 17:4498-4511

Waugh DW, Polvani LM (2010) Stratospheric polar vortices. Geophys Monogr Ser 190:43-57

Xu Y, Castel T, Richard Y, Cuccia C, Bois B (2012) Burgundy regional climate change and its potential impact on grapevines. Clim Dyn 39:1613-1626

Submitted: August 24, 2011; Accepted: November 16, 2013 Proofs received from author(s): February 24, 2014 